\title{
Los ritos, los curanderos y la ley
}

Magdalena Krysińska-Kałużna

Investigadora independiente

Las comunidades indígenas de América Latina han desarrollado conceptos ontológicos intelectualmente ricos, que definen el funcionamiento del mundo en su dimensión física y metafísica. La interpenetración de ambas dimensiones es, en contraste con el concepto "occidental", "positivista" del mundo, bastante obvia. Las reglas que determinan las causas y los efectos de los eventos en los mundos indígenas tienden a ser diferentes de la percepción de estas relaciones en el mundo occidental. Estas reglas muestran claramente los principios que se deben seguir para actuar de un modo racional. ${ }^{1}$

En el texto - el cual está arraigado en la tradición teórica que puede categorizarse como "ontologías indígenas" - voy a presentar la conexión multidimensional de los ritos y rituales, las personas que los realizan y el derecho indígena consuetudinario que funcionan en el campo del conflicto legal en las comunidades indígenas. ${ }^{2}$ En este campo, los sistemas ontológicos indígenas,

1 Sobre la definición de racionalidad y acción racional véase, por ejemplo: BUCHOWSKI 1990: 60-73.

${ }^{2}$ El concepto del campo del conflicto legal significa aquí un conjunto de problemas conectados con el conflicto entre el derecho consuetudinario indígena y el derecho positivo. En las áreas de conflicto en las que se entrelazan diferentes sistemas legales, existen tensiones entre diferentes normas legales, valores, y también convicciones y creencias sobre qué es el derecho, construcciones del mundo y paradigmas que explican su funcionamiento, actitudes con respecto a la comprensión de lo que es una persona, la conciencia, si se puede tener derechos sin cumplir con 
junto con las actividades simbólicas resultantes, entre otras, ritos y rituales, desempeñan un papel destacado e irreducible.

Existe una amplia gama de definiciones de los ritos y rituales. Para los objetivos propuestos en este artículo, propongo adoptar la definición de Victor Turner, según la cual "el ritual es una secuencia estereotipada de actividades, que involucran gestos, palabras y objetos, realizadas en un lugar apartado y diseñadas para influir en entidades o fuerzas sobrenaturales en aras de los objetivos e intereses de los actores". ${ }^{3}$ A su vez, por ritos se entendería aquí los conjuntos de actividades sociales, cuyo sentido principal es manifestar respeto por valores culturales específicos. ${ }^{4}$ Sin embargo, hay que tener en cuenta que las actividades humanas no se dividen claramente en ritos y no ritos, rituales y no rituales; en varias actividades simbólicas, a las que no podríamos denominar, conforme a las definiciones anteriores, como ritos o rituales, anidan también aspectos de estos fenómenos. ${ }^{5}$ Lo que resulta más importante para nosotros, es su efecto "transformador real en individuos y grupos sociales" que tienen estas "formas significadas de representación simbólica".

Cabe señalar que mi intención no es someter a análisis la importancia de los ritos o rituales particulares en detalle, ya que esto requeriría una presentación mucho más amplia de los contextos culturales de la que es posible presentar aquí. Tal explicación ciertamente permitiría al lector comprender mejor el significado de los comportamientos y eventos evocados en el artículo que se originan en varias culturas y comunidades indígenas latinoamericanas. Aunque, afortunadamente, un análisis profundo de estos significados, extremadamente interesantes, no es necesario, para demostrar que 1) la práctica del castigo en su dimensión ritual y 2) la diferencia ontológica de los mundos indígenas (que resultan, entre otros, en la forma de juzgar y ejecutar las sentencias), constituyen elementos importantes, que actúan en el campo del conflicto legal entre el derecho positivo y el derecho consuetudinario indígena. ${ }^{8}$ Eso vendría a significar que la ley basada en la visión del mundo occidental no puede ser una respuesta

obligaciones y si todos merecen los mismos derechos. Más sobre la definición de campo de conflicto legal, véase KRYSIŃSKA-KALUŻNA 2017: 217-227.

3 TURNER 1973: 1100

${ }^{4}$ GRAD 1993: 84; BuRSZTA 1998: 113; para comparar otras definiciones y conceptos de ritos y rituales, véase, por ejemplo: BowIE 2006: 138-173.

5 LEACH 1954: 12-13.

${ }^{6}$ Lincoln 1991: 6; Catherine Bell describe el ritual „,como expresión de valores paradigmáticos de muerte y renacimiento, ritual como mecanismo para traer al individuo a la comunidad y establecer una entidad social; o ritual como el proceso para la transformación social, para la catarsis, para encarnar los valores sociales, para definir la naturaleza de lo real o para luchar por el control del signo y también para ejecutar el poder", BELL 1997: 89.

7 KeRTZer 2010: 115.

${ }^{8}$ KrYSIŃSKA-KALUŻNA 2017. 
adecuada a ciertos acontecimientos que se dan en los mundos indígenas porque estos acontecimientos, en primer lugar, rebasan los límites de racionalidad positivista y, en segundo lugar, no son considerados como un crimen o un delito por la ley nacional. ${ }^{9}$

En la primera parte del texto presentaré ejemplos de ritos de una comunidad rigurosa en grado sumo, los kogi; a continuación, los ritos de los quichua y de los maya, que son minorías numerosas e influyentes en las regiones donde habitan. En la segunda parte, me centraré en ejemplos, en cuanto a la forma de juzgar y ejecutar las sentencias en otra región de América Latina, esto es, en la Amazonía y en sus comunidades indígenas.

\section{LOS RITOS Y LA LEY. EL RITO COMO ASPECTO ESENCIAL DEL CASTIGO}

Los padres de la antropología y la sociología, como Emil Durkheim ${ }^{10}$ y Bronisław Malinowski ${ }^{11}$, ya subrayaron que los estudios sobre la ley se hallaban vinculados a los estudios sobre los ritos y rituales. Durkheim, como Marcel Mauss, de quien había sido colaborador, se dedicó al estudio del origen social y cultural de las ideas jurídicas. En opinión del sociólogo francés, la ley era el resultado de la transformación de las normas morales en normas legales, las cuales están protegidas por sanciones (especialmente en las sociedades "primitivas"). "Por lo general, las costumbres no se oponen a la ley - escribió - sino que, por el contrario, constituyen su fundamento"12. Para el sociólogo francés, la ley es una expresión de costumbres "y si la ley se vuelve contra ellos, lo hace con la fuerza que solo ellos le dan"13. El colectivo crea hechos sociales y los hechos legales les pertenecen. Según Durkheim, la ley es un reflejo de la moral social, que cambia simultáneamente con los cambios en la organización social. A pesar de que algunos de los postulados de Durkheim han perdido su poder de

\footnotetext{
${ }^{9}$ Los lectores interesados en una bibliografía más amplia de publicaciones sobre el derecho consuetudinario indígena (también en el contexto de diferentes ontológicas), pueden consultar mi libro, "Prawo jako mit. Relacja pomiędzy tubylczym prawem zwyczajowym a prawem stanowionym”, KRYSIŃSKA-KAŁUŻNA 2017.

${ }^{10}$ El libro "Les forms elementaires de la vie religieuse Le systeme totemique en Australie" fue publicado en el año 1912.

${ }^{11}$ El libro "Crimen y costumbre en la sociedad salvaje" ("Crime and Custom in Savage Society") de Bronisław Malinowski fue publicado en 1926. El siguiente libro de Malinowski sobre la "ley primitiva", "Ley y costumbre" ("Law and custom"), fue publicado en 1934.

12 Durkheim 1999[1893]: 86, trad. de la Autora.

13 Durkheim 1999[1893]: 186.
} 
persuasión ${ }^{14}$,el concepto de Durkheim puede ser el punto de partida para observar las interrelaciones entre la religión, el rito y la ley.

La percepción de Durkheim se ha analizado durante demasiado tiempo solo en términos de las llamadas ilusiones generadas por estados afectivos de entusiasmo social - dice Catherine Bell. - Sin embargo (...) su declaración puede capturar con precisión la verdad de las relaciones de poder construidas ritualmente, no los delirios de la emoción colectiva. La persona que ha rezado a su dios, apropiándose de los esquemas sociales de un orden hegemónico en términos de una redención individual, puede ser más fuerte porque estos actos son las definiciones mismas del poder, de la personalidad y de la capacidad de actuar. ${ }^{15}$

Echemos entonces un vistazo a la naturaleza ritual de las sanciones y al proceso del juicio, partiendo de la división clásica de las sociedades propuesta por Durkheim.

Según Durkheim, hay dos tipos de organización social con los que se asocian dos tipos principales de leyes. Las sociedades preindustriales y su solidaridad mecánica van aunadas principalmente a leyes represivas. En cambio, la solidaridad orgánica en sociedades complejas entra en el dominio de la ley de restitución.

La superioridad de la ley represiva en condiciones de solidaridad mecánica se debe al hecho de que sirve para mantener la conformidad de los individuos con la comunidad. Un acto criminal es una violación a las normas universalmente obligatorias y comunes para todos, por lo que se encuentra con una reacción social violenta y emocionalmente saturada. En particular, son severamente castigados los crímenes contra la religión porque, como institución fundamentalmente social, [ella] es la base de la vida colectiva de las sociedades simples ${ }^{16}$.

A juicio de Durkheim, la función clave del castigo sería entonces restaurar la cohesión social. ${ }^{17}$

Si hay una comunidad que refleja fielmente los conceptos de Durkheim, donde se vinculan la ley, la religión y los ritos, es, sin duda, la comunidad de los

${ }^{14}$ Andrzej Kojder menciona en este contexto, por ejemplo, la tesis de Durkheim sobre la ley de restitución, en la cual se afirma que las doctrinas legales reflejan los estándares morales que prevalecen en la sociedad; KoJDER 2006: 297.

15 BeLl 2009: 218; trad. de la Autora.

16 WarczoK 2013: 43, trad. de la Autora.

17 Durkheim 2019; véase también: WARCZoK 2013: 44. Examinando rituales, a los pensamientos de Durkheim se referían, reinterpretándolos, entre otros: A.R. Radcliffe-Brown, Meyer Fortes y E.E. Evans-Pritchard, Victor Turner. 
kogi de Sierra Nevada de Santa Marta, tal y como la percibiese e interpretara el antropólogo colombiano Gerardo Reichel-Dolmatoff al estudiar su cultura. ${ }^{18}$

Se cree que los kogi son los herederos directos de la antigua cultura Tairona. Son un pueblo conservador, que siguen a pies juntillas las tradiciones, prohibiciones y órdenes de su cultura. Los kogi viven en un mundo dividido entre aluna ${ }^{19}$ y el mundo de los símbolos, porque las cosas "concretas" tangibles aquí, en "nuestro mundo", son realmente sólo símbolos. Los kogi y sus Hermanos Menores, como les llaman a los "blancos", habitamos en este mundo de símbolos únicamente de forma temporal.

La autoridad más importante en las comunidades kogi son las personas llamadas máma (plural - mámas). Para convertirse en mámas, los candidatos, desde temprana edad, estaban sujetos a una disciplina estricta. Un niño destinado a ser máma (por parentesco u otras razones) era separado de su madre poco después de su nacimiento y criado por otro máma. El bebé era amamantado por la esposa del máma, pero a la edad de tres meses se le destetaba y a partir de ese momento disfrutaba de una dieta especial. Cuando Gerardo Reichel-Dolmatoff, experto en cultura kogi, llevaba a cabo sus investigaciones, al máma se le entregaban niños de dos años o más, que, a fin de prepararse para desempeñar funciones de "sacerdote", vivían en una cabaña separada, dormían durante el día y velaban por la noche. Los candidatos a ser los mámas no podían mirar el sol durante muchos años, ni siquiera por un momento. Cuando Reichel-Dolmatoff visitaba a los Kogi, (les visitó por última vez en la década de 1980), el período de enseñanza para ser máma duraba dieciocho años. ${ }^{20}$

18 Reichel-Dolmatoff 1996; de publicaciones más recientes sobre la vida ritual de los kogi, véase por ejemplo: Drysdale 1994; Duque Cañas, Salazar Gómez, Castaño Alzate 2004; ORRANTIA 2002A y ORRANTIA 2002b.

19 Gerardo Reichel-Dolmatoff escribió que la palabra aluna no es traducible al español. Puede significar espíritu, memoria, pensamiento, vida, voluntad, alma, intención; Reichel-Dolmatoff 1996: 203. Sin embargo, no es ninguna de estas cosas, es decir, no se puede limitar a ninguna de ellas. Es un "lugar" donde hay "verdadero valor y esencia"; Reichel-Dolmatoff 1996: 204.

20 Sobre la comunicación directa de los kogi con los seres no-humanos véase también por ejemplo PARRA Witte (2017: 249-250): "Dado que este entorno de vida 'habla', 'enseña' y 'advierte' a los kogi en la vida cotidiana a través de la adivinación, los signos, los sueños (kabizhitueld), el trueno y otros medios, se entiende que se está comunicando sobre su desestabilización por parte de la actividad del Hermano Menor. Hace mucho tiempo, le dijeron a RecLús (1861: 275) que "la montaña ruge" y tiene "voces", por lo que ahora está rugiendo y, además, se expresa a través del mensaje ecopolítico de los kogi. Basado en sus habilidades clarividentes como ubastunka ("ver con el ojo interno"), Máma Julian afirma comunicarse directamente con las entidades espirituales, que dicen "no estamos bien". (...) Sin embargo, en términos de los kogi, estas voces no humanas constituyen una "Madre" unificada, no sólo como una "personificación de la biosfera" (MiLton 1993: 12) sino del cosmos. "La madre es una persona total", mi amigo Mariano y el portavoz de OGT dijo una vez: "esto no es un juego, es algo profundo". 
La Madre de los kogi es la deidad más importante, la creadora. Todo viene de ella. La ley que debe seguirse también se deriva de ella. La "ley de la Madre" conforma el conjunto de normas que gobiernan el mundo y que deben respetarse, si no queremos exponernos a su severidad. "Ella dijo: „Hay que cuidar al suegro', ,hay que bailar para que venga el verano', ,hay que ayunar', ,no hay que pelear con tu hermano"'. ${ }^{21} \mathrm{El}$ castigo por incumplimiento de la ley es la enfermedad y la muerte. En el mundo de los kogi, la enfermedad proviene del mundo espiritual. Un enfermo kogi bebe mucha agua y trata de apaciguar a quienes le enviaron enfermedades, para salvarse de la muerte. Nadie empatiza con él: es infeliz por haber incumplido la ley. ${ }^{22}$

Los kogi opinan que el individuo tiene más obligaciones que derechos y siempre tiene que seguir las recomendaciones y órdenes de los mámas. Los mámas son quienes aconsejan y aseguran de que se cumpla la "ley de la Madre"; son los guardianes. Ellos son quienes gozan de sabiduría.

La autoridad del Máma abarca prácticamente todas las dimensiones de la actividad de la sociedad y del individuo. Es el Máma quien decide las fechas de la celebración de las ceremonias colectivas y quien las dirige en todas sus detalles. Al encargarse de las ceremonias del ciclo vital, interviene ya más directamente en la vida privada del individuo y por medio de la confesión y de sus subsecuentes castigos domina hasta en lo más mínimo todas las acciones de sus súbditos. ${ }^{23}$

El Máma decide sobre los ritos, los bailes, cuándo uno puede casarse, cuándo y cómo enterrar a un fallecido, cómo curar a un enfermo, construir una casa, cosechar o viajar. A los mámas se les escucha y se les obedece. Quienes no lo hacen, son castigados, y los castigos presentan una forma ritual. Restauran el equilibrio social y rescatan a la persona castigada para una comunidad, de la cual se le ha excluido por no haber observado las reglas. Veamos un ejemplo citado por el antropólogo colombiano: Un hombre de veinte años que caminaba por el monte encontró una casa donde vivía sola una mujer de cuarenta y cinco años, que era la esposa del máma de un asentamiento vecino. El máma había abandonado a su esposa porque esta "comía mucho". El joven se quedó con la mujer. Trabajaban juntos en el campo y también mantenían relaciones sexuales. Cuando el máma se enteró de esto, ordenó llevar a la pareja a su población. El hombre fue sentenciado a permanecer más de catorce horas de rodillas sobre piezas de cerámica rota y con piedras pesadas sobre las manos en alto. Además, el máma le azotó con un palillo en la cabeza hasta que la sangre comenzó a chorrear. Diez hombres rodeaban al joven, al tiempo que le daban

21 Reichel-Dolmatoff 1996: 193.

22 Reichel-Dolmatoff 1996: 265-267.

${ }^{23}$ Reichel-Dolmatoff 1996: 36. 
consejos en forma de citas de historias míticas y también le pinchaban con palillos. La mujer tuvo que pasar toda una noche a la intemperie, desnuda, en el frío y bajo la lluvia. Sus pertenencias y animales le fueron entregados al máma, al que además tuvo que pagarle 16 pesos. Solo después de todo ello, el máma le dijo al joven: "Aquí está tu mujer. Ahora vete con ella". Según la descripción de Reichel-Dolmatoff, el hombre no se sorprendió ni protestó. Dijo: "Me fue mal porque hice algo en contra de todos y así me castigó". ${ }^{24}$

Los demas explicaron el asunto asi: el Máma habia abandonado a la mujer, ella era aun propiedad del Máma y antes de establecer relaciones sexuales con ella se hubiera debido pedir el permiso del Máma. Como no pidió este permiso, se hizo culpable de robo, ya que se apropió la propiedad de un Máma. Puesto que el Máma es el'padre' de todos, todo el grupo de hombres tomó parte en el castigo. ${ }^{25}$

Para los kogi, el atentado contra la "propiedad" del máma es un atentado contra la esencia de esta comunidad, contra la encarnación de su sentido. La restauración del orden requiere un rito apropiado que incluirá a un miembro de la comunidad, de la cual él mismo se ha excluido. Su reincorporación tiene lugar a través de la penitencia infligida por el máma. Una mujer sin sus ropas, que simbolizan su pertenencia a la cultura y la comunidad de los kogi, debe permanecer durante la noche fuera de la comunidad, fuera del hogar, bajo el frío y la lluvia. Esta exclusión unívoca de la comunidad, que le arrebata todo lo que poseía gracias a haber formado parte de la misma (incluidas las gallinas y un perro), hará posible su nueva incorporación, su inclusión. El hombre debe sostener piedras (las piedras grandes simbolizan ancestros ${ }^{26}$ ) y arrodillarse sobre fragmentos de vasos rotos (los vasos de cerámica simbolizan el útero ${ }^{27}$ ). Es golpeado por los miembros de la comunidad y, al mismo tiempo, es aleccionado por ellos. Son los hombres de la comunidad kogi los que detentan el poder de restablecer la conexión entre el delincuente y la comunidad.

"Ritos de paso" similares, la "purificación" simbólica y la inclusión a la comunidad son también practicados por los indígenas quichua de Ecuador. ${ }^{28}$

La cosmología de los quichua se basa en la idea del equilibrio (Pakta Kawsay), que es necesaria para el buen funcionamiento del universo, que es al mismo tiempo el espacio y el tiempo de existencia de todas las

${ }^{24}$ Reichel-Dolmatoff 1996: 49.

25 Reichel-Dolmatoff 1996: 49.

26 Reichel-Dolmatoff 1996: 84.

27 “Todos los recipientes de barro representan el útero", Reichel-Dolmatoff 1996: 73.

${ }^{28}$ Los quichuas están asentados en Ecuador principalmente en ocho de las diez provincias serranas y, en la Amazonía, en tres de las seis provincias orientales. 
entidades vivientes, que se consideran humanos, animales, plantas, fenómenos atmosféricos, objetos físicos ${ }^{29}$,

así como tales categorías y fenómenos como el tiempo, las emociones o los pensamientos ${ }^{30}$.

Romper las reglas implica el castigo. Algunas de las penas son, como entre los kogi, la enfermedad y la muerte.

Las normas de la cultura quichua dictan que uno no debe ser perezoso (ama quilla), no debe mentir (ama llulla) y no debe robar (ama shua). Los quichua creen que cada elemento del universo afecta a todos los demás. El impacto del individuo, a través de su comportamiento apropiado o inapropiado, sobre la situación de la comunidad en la cual vive, es aún más evidente. Una persona que no obedece las reglas del sumak kawsay puede traer la desgracia a toda la comunidad. Según Pedro Solano, presidente de la comunidad de Quilloac, en Cañar, la justicia consuetudinaria busca que el infractor alcance la armonía consigo mismo y con la comunidad. ${ }^{31} \mathrm{La}$ "justicia ancestral" soluciona desde peleas entre esposos, hasta problemas con los hijos, robos, trata de personas y accidentes de tránsito, detalla Rocío Cachimuel, presidenta de la Federación de Indígenas y Campesinos de Imbabura (FICI) - "Para eso tenemos normas, principios y autoridades que aplican sanciones de acuerdo con la gravedad del delito". ${ }^{32}$

Las acciones emprendidas de acorde al derecho consuetudinario quichua, que, siguiendo a Kertzer, podríamos describir como "actividades envueltas en una red de simbolismo" 33 , consisten en cinco pasos. Para nosotros, resulta particularmente interesante la última etapa: paktachina, cumplimiento de la sanción o del castigo. Hay cinco tipos de sanciones: sanción moral (un llamado de atención), sanción física (un baño de purificación y latigazos), sanción económica (reparar el daño causado), el trabajo comunitario y la expulsión de la comunidad. ${ }^{34}$ Las sanciones morales y físicas están entrelazadas y se aplican a la vez.

Por lo general, las sanciones son aplicadas por las autoridades indígenas locales, como el presidente del cabildo, personas mayores o padrinos, hombres o mujeres que son "honestos y respetados". Una de las transgresiones que exige castigo es la traición matrimonial. Esta clase de traición perturba el equilibrio social. En una situación semejante, el grupo decide imponer un castigo, que primero corrobora la exclusión del infiel de la comunidad a través del

29 PrZytomsKa 2012: 68-69; véase también por ejemplo Monosalvas 2014.

30 Przytomska 2012: 69, véase también por ejemplo: Hidalgo-CaPitán, Guillén García, Deleg Guazha (eds), 2014.

${ }^{31}$ Los indigenas... 2014.

${ }^{32}$ Los indigenas... 2014.

33 Kertzer 2010 [1988]: 9.

${ }^{34}$ Manual... 2004: 36-42. 
encarcelamiento (bajo la custodia de la comunidad) y que contempla la posibilidad ulterior de inclusión, cuando el delincuente reciba ya comida de parte de su cónyuge:

A la persona que cometió el problema (adulterio) se le encierra durante 24 horas y no se le da alimentación. Esta sanción se da en el caso de adulterio, quien tiene una amante, no es responsable con la mujer, con los hijos, no respeta al cabildo. Cuando se da el caso de separación del esposo por tener una amante la sanción es encerrarlo en la cárcel por 3 o 4 días, sin ninguna clase de comida, excepto la que le proporciona su verdadera esposa; si recibe algo de comida hasta pasados cinco días, quiere decir que se reconcilian y no va estar con la amante. ${ }^{35}$

El adulterio también puede ser castigado mediante la flagelación. En una de las comunidades quichuas, cada una de tres personas de la comunidad le da tres latigazos al infractor. A parte de eso, el sujeto castigado recibe consejos que le son dados por personas mayores

que pueden ser ex cabildos, como también por algunos representantes religiosos que pueden ser de la iglesia católica, de la iglesia evangélica y la iglesia mormona, de cómo vivir dentro del hogar, de igual manera se le encierra en la cárcel por unos 4 a 5 días. ${ }^{36}$

A veces el castigo se lleva a cabo en un espacio de particular importancia para la cohesión social de un grupo dado.

Luego del consejo al sancionado le acostamos en el escritorio de la oficina, le damos azote, sin quitarle la ropa, en las nalgas y piernas, cada autoridad le da un solo azote (...) [En otras comunidades] el primer látigo es a nombre de Dios Padre, el segundo látigo a nombre de Dios Hijo, y el tercer látigo a nombre del Espíritu Santo. En la ejecución de esta pena no sólo intervienen las autoridades, sino también los familiares, los padres, los padrinos, que primero aconsejan y después dan el látigo. ${ }^{37}$

El azote muchas veces suele ir acompañado de un baño en agua fría y en algunos casos el castigo del fuete y baño suele ir acompañado de una ortigada. ${ }^{38}$

Encontramos ritos parecidos en las sociedades mayas de Guatemala. Según Edgar Esquit Choy y Carlos Ochoa Garcia ${ }^{39}$, todas las normas en la cultura maya hacen referencia al aspecto sagrado (tyox) de cualquier fenómeno. Dentro

\footnotetext{
35 García Serrano y Saltos 2000: 82-83.

36 García Serrano y Saltos 2000: 83.

37 García Serrano y Saltos 2000: 87.

38 García Serrano y Saltos 2000: 87.

39 EsQuit ChOY y ICHOA García 1995.
} 
de la tradición maya, existe un arquetipo para todo rol social y todo comportamiento, ligados a la ley y al respeto por lo sagrado.

Las vidas de los antepasados ofrecen recetas, o planos, sujetos a la sanción divina sobre cómo hacer lo que se debe hacer. Hay que respetar y obedecer a 'los abuelos y las abuelas', así como las reglas de la tradición. ${ }^{40}$

Las normas que gobiernan la vida contemporánea se formaron en el pasado. ${ }^{41}$ La máxima autoridad local la constituyen los ancianos conocidos como $k$ 'amalb'e "los que conocen el camino". ${ }^{42} \mathrm{El}$ mundo es equilibrado y todos deben mostrar respeto por este hecho, obedecer y seguir las formas que mejor aseguren y perpetúen la comunidad.

Las transgresiones del orden son concebidas como pecados y crímenes porque amenazan a toda la comunidad. Las contravenciones causan makaj: pecado, culpa, vergüenza. Makaj también indica la necesidad de purificación o limpieza. ${ }^{43}$

En el mundo maya ${ }^{44}$, como en las otras sociedades ya mencionadas, la enfermedad puede ser un castigo divino y la pena impuesta por la comunidad también es de carácter ritual. Por ejemplo, se dio el caso de una pareja de esposos que "fue azotada e hincada sobre piedrín durante media hora. (...) Líderes comunitarios, que prefirieron el anonimato, comentaron que, desde hace varios meses, obtuvieron información que un hombre y una mujer aseguraban tener poderes para sanar y que ofrecían curar enfermedades a cambio de dinero y ropa típica nueva". Igualmente, entre las mujeres que son castigadas por las comunidades, se encuentran algunas madres que decidieron quedar embarazadas por dinero y luego vender a sus hijos. Se les afeita la cabeza o se les corta públicamente el pelo mientras son azotadas. A veces incluso se las despoja del vestido. ${ }^{45}$

Las estrategias de ritualización del castigo están particularmente arraigadas en el cuerpo; en concreto, la interacción del cuerpo social dentro de un entorno espacial y temporal simbólicamente constituidos ${ }^{46}$. La violación de las reglas y costumbres reconocidas por la sociedad deriva en la respectiva

${ }^{40}$ EKERN 2008: 128.

${ }^{41}$ Esquit ChOY y ICHOA García 1995: 38.

${ }^{42}$ EKERN 2008: 128.

43 EKERN 2008: 128.

${ }^{44}$ Sobre el derecho indígena en la sociedades mayas en México, véase por ejemplo Krotz (ed.) 2015 .

45 Cumes 2009: 105; sobre la relación de poder y género en contexto de ritos de paso, véase LINCOLN 1991.

46 BELL 2009. 
sanción, considerada como un mecanismo de control que permite restablecer la armonía interna del grupo. ${ }^{47}$ "La experiencia del dolor físico es considerada como un medio necesario para poder cambiar, para volver a vivir en armonía". ${ }^{48}$ Lograr este resultado es posible gracias a los esfuerzos de todo el grupo que acompañan la emisión de la sentencia, así como la pena dictaminada. Esencial a la ritualización es la producción circular de un cuerpo ritualizado que, a su vez, produce prácticas ritualizadas. "La ritualización está incrustada dentro de la dinámica del cuerpo definida dentro de un ambiente estructurado simbólicamente". ${ }^{49}$ Podemos decir que el ritual expresa creencias de manera simbólica con el propósito de reafirmarse y aleccionar sin hacer tregua. Esta relación es particularmente prominente en las teorías del ritual como una forma de control social. ${ }^{50}$

El ritual de purificación aborda directamente la tenuidad de la conexión entre el acusado y el supuesto pecado o crimen. En la purificación jerárquica, el ritual nos recuerda que todos estamos conectados igual de tenuemente a los pecados y crímenes, y todos estamos en una comunidad común responsable de asegurar que no hagamos que estas conexiones tenues tengan una mayor responsabilidad por el mal que la nuestra. ${ }^{51}$

El castigo impuesto por la comunidad, sin embargo, no siempre trata de reintegrar al delincuente. A veces, el propósito del castigo es la exclusión de la comunidad. Y en ocasiones la exclusión presenta su forma más extrema: la muerte. Los ejecutados por decisión de la comunidad son sobre todo personas acusadas de brujería. En junio de 2020, cuando terminaba de escribir este artículo, un especialista en medicina maya ${ }^{52}$ y curandero tradicional, Domingo Choc Che, fue asesinado después de haber sido acusado de brujería en su ciudad natal de Chimay, Guatemala. ${ }^{53}$ Choc fue maltratado y luego, aún con vida, quemado. Alguien filmó su muerte, acontecida en un campo de fútbol, que era

${ }^{47}$ García Serrano y Saltos 2000: 74.

48 García Serrano y SALtos 2000: 90; sobre la „violencia de rebote” véase también: Bloch 1986.

49 BeLl 2009: 93.

50 BeLl 2009: 182.

516 y RichARDS 2004: 157-158.

52 Choc Che participó en varios proyectos de investigación científica, también internacionales, sobre medicina maya.

53 "Choc fue señalado por familiares de un hombre muerto tres días antes del incidente en un hospital, de haberlo enfermado con brujería. Agrega que después de la muerte de esa persona, los pobladores comenzaron a vigilar al guía espiritual y que Domingo habría sido sorprendido casi a la medianoche del viernes 'haciendo actos de hechicería, frente al panteón de la persona que murió tres días atrás. Según el parte policial, Domingo Choc fue retenido por cinco personas a las 2 de la madrugada del sábado, que lo ataron durante varias horas para luego prenderle fuego en un campo de fútbol de la comunidad", Mendoza 2020. 
posible ver a través de Internet. ${ }^{54}$ A Adolfina Ocampos, una mujer paraguaya del grupo indígena mbya guaraní, también se la condenó a muerte por brujería. Fue atada a un palo, vejada con flechas y - aún con vida - quemada en una pira. ${ }^{55}$ Casos de linchamientos perpetrados contra las "brujas" y la "brujería" se suceden entre varios grupos indígenas de América Latina.

\section{LOS CURANDEROS Y LA LEY. El CHAMÁN COMO EL JUEZ}

Para los pueblos indígenas, "la realidad", que está en la base de los juicios estatales (nacionales), suele encontrarse muy alejada de la realidad ontológica, en la cual viven los autóctonos. Su realidad está ligada a acontecimientos y personajes míticos, que el concepto "occidental", "positivista", de explicar el mundo, de ninguna manera tiene en cuenta. Por lo general, la ley nacional se asienta de hecho en la racionalidad ilustrada, en tanto que el derecho tradicional (consuetudinario) de los pueblos indígenas, por lo general, no. La realidad social en base a la cual se diseñó la legislación nacional procedente de Europa, no contempla, por ejemplo, la posibilidad de transformación de una criatura en otra (de un hombre en un jaguar, en un pájaro o en un relámpago), mientras que tales transformaciones tienen cabida en los mundos indígenas. ${ }^{56}$ De acuerdo con las creencias existentes en muchas culturas latinoamericanas, en los procesos que devienen en el mundo se hallan involucrados fantasmas, brujos y otras fuerzas, "sobrenaturales" en términos "occidentales" ,y lo más "naturales" posible en términos "indígenas". En las imágenes del mundo elaboradas por la ilustración y el positivismo dichas criaturas realmente no existen, y por lo tanto no pueden ser ni objetos ni sujetos de derecho. ${ }^{57}$

La interferencia de los seres y poderes no humanos en el mundo humano y las transformaciones de animales en seres humanos son evidentes por ejemplo para las culturas indígenas de la Amazonía. En estas culturas el mundo no es definitivamente demarcado y dividido entre humano y no-humano y los "actos" de la gente no se limitan únicamente a las actividades que ellos hacen cuando estan en su cuerpo humano. ${ }^{58}$ Esto posibilitaría que personas con capacidad de transformarse en otros seres puedan transmitir enfermedades y provo-

${ }^{54}$ Según un informe del Grupo de Apoyo Mutuo, una organización humanitaria, en Guatemala los linchamientos causaron al menos 354 muertos y 1258 heridos entre 2008 y 2018: https://issuu.com/grupodeapoyomutuogt/docs/linchamientos_una_d_cada (31.05.2020)

${ }^{55}$ Paraguay woman... 2014.

56 Viveiro de Castro 2004.

57 KrYsińSKA-KaluŻNa 2017.

58 Viveiro de Castro 2004. 
car la muerte. Verbigracia, en la ontología y cosmopolítica de los suruahá de la Amazonía brasileña:

Por un lado, no se considera la muerte como derivada de causas naturales: morir (mazaruri) es consecuencia de un hechizo (mazaru). Toda muerte es homicidio, provocado por la acción chamánica o en el ámbito de la hostilidad generalizada en el horizonte de afinidad potencial, de alteridades peligrosas - no es diferente para los suruwaha, para quienes la muerte por enfermedad, picadura de serpiente, ataque de fieras o ingestión de venenos es producto de la agresión de agentes depredadores. En rigor, todos los muertos son 'presas del hechizo' - mazarubahi. (...). Por otro lado, en las sociedades amazónicas existen narrativas sobre el origen de la mortalidad que proyectan la inevitabilidad de la muerte como un hecho 'natural'. ${ }^{59}$

Lanzar hechizos y neutralizarlos es tarea de los chamanes, los cuales

emergen como mediadores por excelencia, como los agentes de una cosmopolítica y, sobre todo, como aquellos que disponen de ciertas capacidades de acción y transformación, potencializadas por las relaciones que ellos mantienen con los agentes - no humanos, invisibles - del cosmos. ${ }^{60}$

La información sobre la identidad del autor del hechizo a menudo viene al chamán durante la curación de la víctima. Un buen ejemplo de este proceso, conectado con el juicio, sería el de la curación entre los indígenas huitoto, tal y como se describe a continuación:

Los huitoto para curar utilizan la corteza de la cumala o úcue, un árbol de la selva. La muelen, la cocinan dos días y la mezclan con esencia de tabaco chapeado. Esta especie de mermelada se llama ampiri. La persona que se dispone a realizar el proceso de curación, el aima, gracias al ampirino no sólo logrará cumplir con este objetivo, sino que también vislumbrará quien hizo brujería. Durante la sesión curativa aparece una muchedumbre de seres: un espíritu úcue-máma (madre de cumala), los espíritus malos de otros brujos que tratan de interrumpir la sesión, ciempiés, grillos, abejas, los espíritus tunun $+a+$ (que se parecen a sapos venenosos), los espíritus en forma de humanos, que se llaman sinchirumichi y son hombres del espacio y muchos otros de entre los cuales se presentan los espíritus de ancestros, llamados usumac + , que el aima convoca a fin de que le protejan de los malos espíritus deseosos de entrar y hacerle daño. Los usumac serán precisamente quienes ayudarán al aima a reconocer al

59 Aparicio 2015: 208-209. Esta sería la paradoja identificada por Taylor en las etnografías de las TIERRAS bajas de América del Sur; TAYLOR 1996.

${ }^{60}$ SzTUTMan 2012: 454. 
espíritu del brujo culpable del perjuicio realizado contra la persona enferma. ${ }^{61}$ En suma, durante el proceso de curación, el chamán descubre quién es el culpable.

El uso de hechizos también desempeña un papel importante en la sociedad de los indígenas peruanos awajún (aguaruna). Simone Garra relata una historia muy interesante a propósito de los certificados emitidos en esta comunidad a sus miembros, destinados a confirmar que el interesado no practica conjuros de hechizo, dañinos para los demás. ${ }^{62}$

La concepción de enfermedad está relacionada en la cultura awajún con el complejo de los dardos mágicos (tsentsak) característico de la Amazonía noroccidental. Desde hace unos treinta años, este concepto tradicional ha sido asociado, entre los awajún, al llamado vegetalismo y otras nuevas prácticas mágicas. No obstante, las actividades de índole más o menos tradicional de los hechiceros todavía están presentes y son completamente obvias. Tales usos siempre estuvieron vinculados a relaciones entre nexus particulares, es decir, grupos dentro de la comunidad awajún. Matar a alguien con hechizos requiso y requiere la venganza. Garra habla sobre tres posibles escenarios con respecto al trato dado a un sospechoso de hechizos malignos.

El primero de ellos se refiere a la consulta informal con una persona llamada iwishin, que generalmente es un chamán o un vegetalista awajún o wampis o un curandero mestizo. Esta persona puede, a petición del paciente, revelarle la identidad del causante de su enfermedad. En el segundo escenario, una comisión oficial de la comunidad escoltará al acusado con brujería, para que el iwishin decida si es un hechicero o no lo es. Este evento y el juicio del testigo serán registrados en el Libro de Actas de la comunidad; en el caso que se decrete su inocencia, el certificado será emitido por el iwishin y los testigos, que suelen ser personas con funciones oficiales en el seno de la comunidad (líder $a p u$, representantes de la policía comunitaria, etc.). En la tercera situación posible, si en un lugar ocurren muchas enfermedades o muertes, toda la comunidad contribuirá a los gastos para hacer llegar hasta ella a un iwishin independiente, quien, una vez allí, localizará al culpable, al brujo. Las prácticas del chamán en esta situación también son públicas, registradas en el Libro de Actas, y, descubierto el hechicero, este es expulsado de la comunidad. ${ }^{63}$

Igualmente, en la cultura de los sápara, el chamán puede reconocer a la persona que causó la muerte o la enfermedad. En el año 2013, Imatiña, indígena sápara, informó a un notario de la ciudad de Puyo, sobre una amenaza de hechizos contra varias familias. Las amenazas habían sido pronunciadas

${ }^{61}$ Comulllama Yahuarcani 2005.

${ }^{62}$ Garra 2016.

${ }^{63}$ En casos de culpa probada, también hay asesinatos de chamanes declarados culpables. 
públicamente, durante una reunión de la comunidad, por una persona que era presidente de NASE, la organización local de los sápara, y al mismo tiempo vicepresidente del consejo parroquial de Río Tigre. Tres días después, el hijo de Imatiña murió en extrañas circunstancias: durante una cacería se apartó del grupo a unos treinta metros y después de un tiempo fue hallado muerto "con el cuello y el pecho fracturado por un golpe, en la cara tenía la marca de una mano y los labios cortados". ${ }^{64}$ Imatiña llamó de inmediato a diferentes instituciones sin resultado alguno. Nadie acudió al lugar donde habían matado a su hijo y tampoco vio su cuerpo.

Las amenazas Imatiña habían sido la consecuencia directa de su actitud negativa hacia la extracción de petróleo en la zona. Para explicar la causa de la muerte de su hijo, Imatiña y sus familiares pidieron ayuda a chamanes, residentes en diferentes regiones de Ecuador. Ellos desvelaron que el presidente de NASE había contratado a alguien para matarlo a él y a su esposa, y no a su hijo. El chamán actuó con la ayuda de un ser espiritual llamado supay. Supay cometió un error y mató a otra persona cual no iba a matar el chamán.

\section{Conclusiones}

Mi intención era presentar las formas rituales de juzgar y castigar, que podemos ubicar en los campos del conflicto legal entre las leyes de las comunidades indígenas y leyes nacionales en América Latina, y también demostrar que la ley basada en la visión del mundo occidental no puede ser la respuesta adecuada a los diversos acontecimientos, que se suceden en los mundos indígenas. El poder de los rituales y la inadecuación de la aplicación de la ley nacional en los casos discutidos, están arraigados en diferencias ontológicas condicionadas culturalmente.

Uno de los elementos característicos de las comunidades tradicionales y su funcionamiento social son los ritos de paso descritos por Arnold van Gennep y analizados, entre otros, por Edmund Leach. Estos ritos hacen posible atravesar las fronteras sociales, ya que se produce el pase de un estatus social a otro. ${ }^{65}$ En las sociedades aquí mencionadas, el castigo cobra asimismo una forma y un significado rituales. Los ritos que acompañan la ejecución del castigo en muchas comunidades indígenas latinoamericanas ostentan la misma función inclusiva-exclusiva. La persona que hizo un acto condenable por la sociedad cambia su estatus social. El comportamiento desviado necesita ser corregido. La

${ }^{64}$ VAllejo y Duhalde 2016: 2019.

65 VAN GENNEP 2006 [1909]; LEACH 1989 [1976]. 
violación grave de las normas sociales debe ser sancionada. Tras la exclusión del grupo al cual anteriormente perteneciera como miembro de pleno derecho, el autor o la autora del delito tendrá que someterse a un rito inclusivo, si es que quiere retornar a su comunidad. En el rito participará todo el grupo, o sus representantes, que simbolizan la autoridad secular o religiosa, o como en el caso de los kogi, que realizan ambas funciones simultáneamente. El rito de paso no solo anuncia el cambio, sino que también lo causa de facto. La persona sometida al castigo pasa por un cambio de estatus. Este cambio se expresa de manera ritualizada por un desplazamiento en el espacio (por ejemplo, la custodia de la comunidad), el lavado ritual, el afeitado (eliminación de "impurezas"), el despojamiento de la ropa, la destrucción de los objetos de ofrenda. "El efecto principal de estos ritos preliminares de separación es excluir al iniciado de la vida normal; él (ella) periódicamente se convierten en algunas personas anormales que existen en un tiempo anormal" ${ }^{66}$ La siguiente etapa radica en la producción de un intervalo de atemporalidad social; en la tercera fase, la persona entregada al rito ya está lista para su regreso a la sociedad. "Desde la cosmovisión indígena, el castigo físico y el perdón ante la comunidad - dice Jaime Vintimilla - sirve como herramienta disuasiva, que se traduce en una verdadera rehabilitación". ${ }^{67}$ Estos ritos y rituales, como todos otros ritos de paso, "transforman a las personas, reemplazando roles, estados e identidades viejos por otros, nuevos". ${ }^{68}$

La ritualización es también una estrategia para la construcción de ciertos tipos de relaciones de poder efectivas dentro de organizaciones sociales particulares. Un ritual contiene dos proposiciones clave: “(1) La creatividad no es el producto de la acción humana, sino que se debe a una fuerza trascendental que está mediada por la autoridad, y (2) este hecho legitima, incluso exige, la conquista violenta de los infiernos por parte de superiores que están más cerca de los antepasados trascendentales". ${ }^{69}$ Por consiguiente, la misma relación de poder determina también el proceso de curación. A través de los ejemplos presentados, puede comprobarse que el chamán o curandero en las comunidades indígenas de la Amazonía cumple el papel no sólo de "doctor", persona que cura, sino también de juez, la persona que juzga. El chamán revela quien es culpable de varias desgracias o tragedias que ocurren. Él puede entrar en la esfera donde están los seres y las fuerzas que no pertenecen al mundo donde hay tribunales y jueces mestizos. En esta última zona no hay cabida para figuras míticas y otras personas que pueden tomar la forma de otros seres o así ser percibidas. La enfermedad causada por estos seres, por el espíritu del chamán o los muertos

\footnotetext{
${ }^{66}$ LeACH 1989 [1976]: 81.

${ }^{67}$ La justicia indígena...

${ }^{68}$ LinCOLN 1991: 6.

${ }^{69}$ BLOCH 1986: 189.
} 
antepasados de los kogi, carece del significado semántico, que se corresponde con el "acto legal", en el sentido de la teoría jurídica contemporánea asentada sobre la racionalidad positivista europea. Los tribunales ecuatorianos no pudieron, por lo tanto, lidiar con la muerte del hijo de Imatiña, el indígena sápara perseguido por supay, a despecho de los muchos esfuerzos del padre. En todos los casos, el autor del acto es un ser humano con su voluntad, aun cuando su manifestación material sea una bola de fuego o una violenta tormenta.

En América Latina existe un "desajuste" ontológico entre dos mundos, sobre los que se basan dos diferentes sistemas legales. La ley fundamentada en la visión del mundo occidental no puede dar una respuesta adecuada a los acontecimientos, que rebasan los límites de su racionalidad, ni ofrecer una explicación a las relaciones que sobrevienen en el mundo. Y aunque, como afirma la autora de "Pureza y peligro", no se puede hablar de metafísica sin un contexto político, ${ }^{70}$ tampoco se puede hablar de los principios del derecho sin un contexto ontológico y sin el mundo de los rituales y los ritos asociados a este contexto.

\section{BibLIOGRAFÍA}

APARICIO 2015 - M. Aparicio, Presas del veneno. Cosmopolítica y transformaciones Suruwaha (Amazonía occidental). Cuenca-Ecuador: Abya-Yala, 2015.

Bell 1997 - C. Bell, Ritual Perspectives and Dimensions. Oxford and New York: Oxford University Press, 1997.

Bell 2009 - C. Bell, Ritual theory, ritual practice. Oxford, New York: Oxford University Press 2009.

Bloch 1986 - M. Bloch, From Blessing to Violence. History and Ideology in the Circumcision Ritual of the Merina of Madagascar. Cambridge and New York: Cambridge University Press, 1986.

BowIE 2006 - F. Bowie, The Anthropology of Religion. An introduction, Malden, Oxford, Victoria: Blackwell Publishing 2006.

Buchowski 1990 - M. Buchowski, Racjonalność, translacja, interpretacja. O badaniu myślenia filozoficznego $w$ antropologii i filozofii brytyjskiej, Poznań: Wydawnictwo Naukowe PWN, 1990.

Burszta 1998 - W. J. Burszta, Antropologia kultury, Poznań: Zysk i S-ka Wydawnictwo s.c., 1998.

${ }^{70}$ Douglas 1966. 
Comulllama Yahuarcani 2005 - S. Comuillama Yahuarcani y R. Comuillama Yahuarcani, "Sesión de ampiri de cumala", en: G. Landolt (ed.), El ojo que cuenta. Lima: IKAM Asociación Editorial 2005, pp. 53-57.

Cumes 2009 - A. Cumes, „Sufrimos vergüenza”: mujeres k'iche' frente a la justicia comunitaria en Guatemala," Desacatos, núm. 31, septiembre-diciembre, pp. 99-114 http://www.redalyc.org/articulo. oa? id=13911833007 (acceso: 31.05 .2020 )

Douglas 1966 - M. Douglas, Purity and Danger. An analysis of the concepts of pollution and taboo. London and New York: Routledge, 1966.

DrYSDAle 1994 - H. Drysdale, Guardians of the Sacred Land. London: Survival International, 1994.

Duque Cañas, Salazar Gómez, Castaño Alzate 2004 - J.P. Duque Cañas, O. Salazar Gómez, G.E. Castaño Alzate, Saminashi: Arquitectura y Cosmogonía en la Construcción Kogi, Bogotá, Manizales: Universidad Nacional de Colombia, 2004.

Durkheim 1999 [1893] - E. Durkheim, O podziale pracy społecznej, E. Tarkowska (ed.) Warszawa: Wydawnictwo Naukowe PWN, 1999.

DurkheIM 2019 [1895] - E. Durkheim, Zasady metody socjologicznej, Warszawa: Wydawnictwo Naukowe PWN, 2019.

EKERN 2008 - S. Ekern, "Are Human Rights Destroying the Natural Balance of All Things? The Difficult Encounter between International Law and Community Law in Mayan Guatemala", en: P. Pitarch, S. Speed, X. Leyva Solano (eds.), Human Rights in the Maya Region. Global Politics, Cultural Contentions, and Moral Engagements, Durham and London: Duke University Press, 2008, pp. 123-143.

EsQuit ChOY y OchoA García 1995 - Edgar Esquit Choy y Carlos Ochoa García (eds.) Yiqalil q'anejkunimaaj Tzij niman tziji, El respeto a la palabra: El orden jurídico del pueblo maya, Guatemala City: CECMA, 1995.

García Serrano y Saltos 2000 - F. García Serrano, V. Saltos C., "Formas indígenas de administración de justicia: Tres estudios de caso de la nacionalidad quichua de la sierra y amazonía Ecuatoriana" en: A. M. Bernal (Compiladora), De la exclusión a la participación: Pueblos Indígenas y sus derechos colectivos en el Ecuador, Quito: Abya-Yala, 2000, pp. 71-106.

GARRA 2016 - S. Garra, "Entre la brujería y la ley: los certificados de un iwishinawajún", en: A. Surrallés, O. Espinoza, D. Jabin (eds.), Apus, Caciques y presidentes. Estado y política indígena amazónica en los países andinos, Copenhague: IWGIA 2016, pp. 195-213. 
VAN GENNEP 2006 [1909] - A.van Gennep, Obrzędy przejścia. Warszawa: PIW 2006.

Grad 1993 - J. Grad, Obyczaj a moralność. Próba metodologicznego uporzadkowania badań dotychczasowych, Poznań: Wydawnictwo Naukowe UAM 1993.

Hidalgo-Capitán, Guillén García, Deleg Guazha 2014 - A. L. Hidalgo-Capitán, A. Guillén García, N. Deleg Guazha (eds.) Sumak Kawsay Yuyay. Antología del Pensamiento Indigenista Ecuatoriano sobre Sumak Kawsay. Huelva y Cuenca: FUCHU 2014.

La justicia indígena... - "La justicia indígena evoca un ritual que va más allá de la ortiga, el agua helada y el latigazo", https://www.primicias.ec/ noticias/sociedad/justicia-indigena-ortiga-agua-helada-otavalo/ (acceso: 31.05 .2020$)$.

KerTZER 2010 [1988] - D. I. Kertzer, Rytuat, polityka, władza. Warszawa: Oficyna Wydawnicza Volumen, 2010.

KoJder 2006 - A. Kojder, „Czytając Durkheima... Co klasyk socjologii ma do powiedzenia o prawie", en: Prawo, władza, społeczeństwo, polityka. Ksiega jubileuszowa profesora Krzysztofa Pałeckiego, Kraków: Wydawnictwo Adam Marszałek, 2006, pp. 286-299.

Krotz 2015 - E. Krotz (ed.), Sociedades mayas y derecho. San Cristóbal de Las Casas/ Mérida: Programa de Investigaciones Multidisciplinarias sobre Mesoamérica y el Sureste, México/Mérida: Instituto de Investigaciones Antropológicas, Universidad Nacional Autónoma de México, Universidad Modelo, 2015.

KrysińsKa-KaŁuŻna 2017 - M. Krysińska-Kałużna, Prawo jako mit. Relacja pomiędzy tubylczym prawem zwyczajowym a prawem stanowionym. Kraków, Nomos 2017.

Leach 1954 - E. Leach, Political Systems of Highland Burma. Boston, Beacon, 1954.

LEACH 1989 [1976] - E. Leach, „Kultura i komunikowanie”, en: E. Leach, A. J. Greimas (eds.), Rytuat i narracja, Warszawa: PIW 1989, pp. 21-98.

LINCOLN 1991 - B. Lincoln, Emerging from the Chrysalis: Rituals of Women's Initiation. New York and Oxford: Oxford University Press, 1991.

Los indígenas... 2014 - "Los indígenas en Ecuador tienen su estructura judicial", El Comercio, 24 de agosto de 2014. https://www.elcomercio. com/actualidad/indigenas-ecuador-estructura-judicial-castigo.html (acceso: 31.05.2020).

Manosalvas 2014 - M. Manosalvas, "Buen vivir o sumak kawsay. En busca de nuevos referenciales para la acción pública en Ecuador." Íconos. Revista de Ciencias Sociales, Núm. 49, Quito, mayo 2014, pp. 101-121. 
Manual... 2004 - Manual de administración de justicia indigena en el Ecuador, L. Tibán, R.Ilaquiche (ed.). Quito: IWGIA, Fudeci Cotopaxi, 2004.

Mendoza 2020 - M. Mendoza, Detienen a 4 personas en Guatemala tras el homicidio de un guía espiritual, CNN, 9 junio, 2020. https://cnnespanol.cnn.com/2020/06/09/alerta-detienen-a-4-personas-en-guatemala-tras-el-homicidio-de-un-guia-espiritual/ (acceso: 9.06.2020).

Milton 1993 - K. Milton, Environmentalism: The View from Anthropology, London: Routledge 1993.

Orrantia 2002a - J.C. Orrantia, "Esencialismo desde el Corazón del Mundo. Información como legitimación del riesgo", Revista de Antropología y Arqueología, 13: 45-77, 2002.

OrRantia 2002b - J.C. Orrantia, "Matices Kogi: Representaciones y negociación en la Marginalidad", Revista Colombiana de Antropología, 38: 54-75, 2002.

Paraguay woman... 2014 - Paraguay woman shot with arrows, burned alive for 'witchcraft', RT, 6.11.2014. https://www.rt.com/news/202823-paraguay-witchcraft-woman-burned/ (acceso: 31.05.2020).

Parra Witte 2017 - F.X. Parra Witte, Living the Law of Origin: The Cosmological, Ontological, Epistemological, and Ecological Framework of Kogi Environmental Politics, Downing College University of Cambridge (dissertation submitted for the degree of Doctor of Philosophy in Social Anthropology), 2017.

Przytomska 2012 - A. Przytomska, „Relacja medycyny andyjskiej i brujería w kontekście współczesnych praktyk leczniczych i kosmowizji Indian Kiczua z Andów ekwadorskich”, Indígena, nr 1: 64-87, 2012.

Reclus 1861 - E. Reclus, Voyage à la Sierra-Nevada de Sainte-Marthe: Paysages de la Nature tropicale, Paris: Hachette, 1861.

Reichel-Dolmatoff 1996 - G. Reichel-Dolmatoff, Los Kogi de Sierra Nevada, Palma de Mallorca, Bitzoc, 1996.

6 y RichaRds 2004 - Perri 6 and Paul Richards, "Mary Douglas: Understanding Social Thought and Conflict", Journal of Ritual Studies,18(2):152-191, 2004.

Sztutman 2012 - R. Sztutman, O Profeta e o Principal. A Ação Política Ameríndia e seus Personagens. São Paulo: Edusp, 2012.

Turner 1969 - V.W. Turner, The Ritual Process. Structure and Anti-Structure, Chicago: The University of Chicago Press 1969.

Turner 1973 - V.W. Turner, "Symbols in African Ritual", Science, New Series, Vol. 179, No. 4078 (Mar. 16, 1973), pp. 1100-1105. 
TAYLOR 1996 - A.C. Taylor, "The Soul's Body and Its States: An Amazonian Perspective on the Nature of Being Human." The Journal of the Royal Anthropological Institute, 2 (2): 201-215, 1996.

VAllejo y Duhalde 2016 - I. Vallejo, C. Duhalde, "Chamanismo, petróleo e itinerarios legales inconclusos en la Amazonía de Ecuador", en: A. Surrallés, O. Espinoza, D. Jabin (eds.), Apus, Caciques y presidentes. Estado y política indígena amazónica en los países andinos, Copenhague: IWGIA 2016, pp. 215-234.

Viveiros de Castro 2004 - E. Viveiros de Castro, "Perspectivismo y multinaturalismo en la América indígena", en: Tierra adentro. Territorio indígena y percepción del entorno, A. Surrallés, P. García Hierro (eds.), IWGIA, Copenhague 2004, pp. 37-80.

WARCZOK 2013 - T. Warczok, "Durkheimowska Socjologia Prawa", en: Leksykon Socjologii prawa, A. Kociołek-Pęksy, M. Stępień (red.) 2013, pp. 43-50.

\title{
Recursos electrónicos
}

Grupo de Apoyo Mutuo https://issuu.com/grupodeapoyomutuogt/docs/linchamientos_una_d_cada.

\begin{abstract}
Summary
Rites, healers and the law

The ontological difference on which positive law and indigenous customary law in Latin America are based is one of the most important problems in the field of legal conflict between both systems. The ontological difference of the indigenous world is visible, among others, in the ways of passing and executing sentences. Punishment is often ritualistic and re-integrates the punished person into the community. In many cultures where witcheraft is a common phenomenon, sentences are given by shamans and healers. Illustrating the above statements with examples from various Latin American indigenous cultures, the article shows that law based on the vision of the Western world often cannot be an adequate response to some events taking place in indigenous worlds. This is not least because in the world of positivist rationality these events or phenomena simply do not exist.
\end{abstract}

Keywords: field of legal conflict, rite, punishment, Indians, Latin America 


\section{Streszczenie}

\section{Obrzędy, uzdrowiciele i prawo}

Odmienność ontologiczna, na której opierają się prawo stanowione i tubylcze prawo zwyczajowe w Ameryce Łacińskiej, jest jednym z ważniejszych problemów występujących w polu konfliktu prawnego pomiędzy obydwoma systemami. Odmienność ontologiczna świata tubylczego widoczna jest m.in. w sposobach wydawania i wykonywania wyroków. Kara ma często charakter rytualny, ponownie włączający osobę karaną do społeczności. W wielu kulturach, w których czary są zjawiskiem powszechnym, wyroki wydawane są przez szamanów i uzdrowicieli. Ilustrując powyższe stwierdzenia przykładami z różnych kultur tubylczych Ameryki Łacińskiej, artykuł wykazuje, że prawo oparte na wizji świata zachodniego niejednokrotnie nie może być adekwatną odpowiedzią na różne wydarzenia mające miejsce w światach tubylczych. Dzieje się tak choćby dlatego, że w świecie racjonalności pozytywistycznej wydarzenia te lub zjawiska po prostu nie istnieją.

Słowa kluczowe: pole konfliktu prawnego, obrzęd, kara, Indianie, Ameryka Łacińska 